ఠ

\title{
Immunotherapy combined with epidermal growth factor receptor-tyrosine kinase inhibitors in non-small-cell lung cancer treatment
}

This article was published in the following Dove Press journal:

OncoTargets and Therapy

\author{
Hongge Liang \\ Xiaoyan Liu \\ Mengzhao Wang \\ Department of Respiratory Medicine, \\ Peking Union Medical College \\ Hospital, Dongcheng District, Beijing \\ 100730, China
}

\begin{abstract}
In recent years, targeted therapy and immunotherapy have played important roles in the treatment of patients with non-small-cell lung cancer (NSCLC). Drugs that target epidermal growth factor receptor (EGFR) mutations (eg, gefitinib, erlotinib, icotinib, and osimertinib) are among the most commonly used targeted therapies. Afatinib is an irreversible second-generation EGFR-tyrosine kinase inhibitor (EGFR-TKI), and the LUX-Lung 3 trial demonstrated the superiority of afatinib to cisplatin and pemetrexed in the frontline treatment of treatment-naïve patients with advanced EGFR mutation adenocarcinoma of the lung. Although these drugs show significant therapeutic efficacy, most patients invariably experience disease progression resulting in death. Immunotherapy targeting programmed death-1 (PD-1)/programmed death-ligand 1 (PD-L1) has now been approved for the first-line treatment of patients with advanced NSCLC. These can produce sustained clinical responses by reversing negative regulators of T-cell function; however, immunotherapy response rates remain low, and only a few patients ultimately benefit from this approach. Here, we discuss the potential of EGFR-TKIs for inducing antitumor immunity and the feasibility of their combination with immunotherapy (including PD-1/PD-L1 inhibitors) in NSCLC patients and the associated challenges for clinical application.
\end{abstract}

Keywords: non-small cell lung cancer, epidermal growth factor receptor-tyrosine kinase inhibitors, immunotherapy

\section{Introduction}

Lung cancer is the main cause of cancer-related deaths worldwide. Non-small-cell lung cancer (NSCLC), which accounts for approximately $85 \%$ of all lung cancer cases, is often diagnosed at a late stage and has a poor prognosis. ${ }^{1}$ EGFR is a member of the erythroblastosis oncogene B (ErbB)/human EGFR (HER) family. The family includes four tyrosine kinase receptors in humans: HER1 (EGFR/ErbB1); HER2 (Neu/ErbB2); HER3 (ErbB3); and HER4 (ErbB4). ${ }^{2}$ After EGFR binds to its ligand (EGF or transforming growth factor- $\alpha$ ), the receptor is phosphorylated, forms a dimer, activates the downstream signaling pathway, and transmits signals to the nucleus via Ras-Raf-MEK and $\mathrm{P} 13 \mathrm{~K} / \mathrm{Akt}$ pathways; these control cell proliferation, differentiation, apoptosis, invasion, and angiogenesis. ${ }^{3,4}$ EGFR is overexpressed in many tumors, such as those present in patients with lung cancer, colon cancer, stomach cancer, pancreatic cancer, bladder cancer, prostate cancer, ovarian cancer, and head and neck cancer. ${ }^{3-6}$ The abnormal activation of EGFR in tumor cells is currently thought to involve the following three mechanisms: 1) overexpression of nonligand-dependent EGFR; 2) point or deletion mutation of the gene encoding the EGFR tyrosine kinase activation domain; 3 ) tumor cell overexpression of transforming growth factor- $\alpha$, which activates the EGFR.,7-10
Correspondence: Mengzhao Wang Peking Union Medical College Hospital, No I Shuanfuyuan Wangfujing, Dongcheng District, Beijing 100730, China

Tel +86 I39 II 235467

Email drwang_pumch@sina.com 
Tyrosine kinase inhibitors (TKIs) can significantly improve clinical outcomes in patients with NSCLC associated with EGFR mutations or anaplastic lymphoma kinase (ALK) and ROS proto-oncogene 1 rearrangements. ${ }^{11-21}$ However, these genetic changes only occur in some patients with NSCLC (mainly adenocarcinoma); even if the treatments are initially effective in these patients, the tumors will inevitably develop drug resistance and the resultant disease progression will ultimately require the use of standard chemotherapy. ${ }^{22-24}$ Firstgeneration (gefitinib and erlotinib) and second-generation (afatinib) EGFR-TKIs have shown advantages over platinum-based chemotherapy in NSCLC patients with EGFR mutations, producing higher response rates (RRs) and longer periods of progression-free survival (PFS). ${ }^{13}$ Dacomitinib is another second-generation EGFR-TKI that was reported to show significant improvement in overall survival (OS) in a Phase III randomized study compared with a standard-of-care TKI (95\% CI, 0.582-0.993; two-sided $P=0.044) .{ }^{25}$ However, the majority of patients treated with EGFR-TKIs eventually develop acquired resistance. ${ }^{26-28}$ Therefore, new treatment strategies for patients with NSCLC are urgently needed.

Immunotherapy provides another important treatment for NSCLC. In particular, complete activation of $\mathrm{T}$ cells is regulated by a "dual-signal" system. The first signal involves $\mathrm{T}$-cell recognition of antigen and is derived from the specific binding of the T-cell receptor to the major histocompatibility complex. The second signal is mediated by the interaction of a costimulatory molecule expressed by the antigen-presenting cell, with the corresponding receptor on the $T$ cell. In addition, there are also negative costimulatory molecules that limit $\mathrm{T}$-cell stimulation. These mainly act via the cytotoxic T-lymphocyte-associated antigen-4-B7 (CTLA4-B7) pathway and the programmed cell death protein-1 (PD-1)/programmed cell death protein-ligand 1 (PD-L1) pathway. PD-1 (CD279) is an important immunological checkpoint. It can inhibit the activation of $\mathrm{T}$ cells and the production of cytokines by binding to its two ligands, PD-L1 (B7-H1/CD274) and PD-L2 (B7-DC/CD273), and plays an important role in maintaining peripheral tolerance. Tumor cells and the tumor microenvironment can escape the immune system by upregulating PD-L1 expression and binding to PD- 1 on the surface of tumor-specific $\mathrm{CD} 8^{+} \mathrm{T}$ cells to limit the host's immune response. At present, the most widely studied and used immunological checkpoint inhibitors include monoclonal antibodies raised against CTLA-4, PD-1, and PD-L1; these can reactivate the T-cell-mediated immune response to the tumor by suppressing immune checkpoints and thereby produce antitumor effects. Blockade of the PD-1/PD-L1 signaling pathway using monoclonal antibodies raised against PD-1/PD-L1 has shown excellent antitumor efficacy in a variety of solid tumors. ${ }^{29,30}$ To date, multiple anti-PD-1/PD-L1 antibodies have been approved by the Food and Drug Administration for first- and second-line treatment of patients with advanced NSCLC and have been shown to significantly improve clinical prognosis. ${ }^{31-35}$ For example, a PD-1 antibody (pembrolizumab) in combination with carboplatin and pemetrexed was approved for first-line combination therapy as well as for first-line treatment of metastatic nonsquamous cell NSCLC. ${ }^{36}$ However, immunotherapy is only effective for a small number of patients, and some patients who respond initially show a subsequent rapid disease progression. Therefore, a key challenge in lung cancer research is the discovery of prognostic biomarkers to guide the selection of patients most likely to benefit from this treatment; this requires detailed elucidation of the mechanisms underlying the interactions between tumors and immune cells. ${ }^{37}$

The NSCLC mutation load can affect the tumor immunogenicity. Thus, targeted therapy can enhance the antitumor immune responses by releasing new antigens, ${ }^{38}$ this provides a theoretical basis for immunotherapy combined with targeted therapy. At present, immunotherapy combined with targeted therapy in NSCLC patients is still at an immature phase, and its effectiveness and safety have mainly been assessed by preclinical studies and early clinical trials. In this review, we summarize these early findings relating to the use of immunotherapy and EGFR-TKIs for the treatment of advanced NSCLC. This overview highlights both the progress made in this field to date and the remaining challenges.

\section{Preclinical studies of EGFR-TKIs plus immunotherapy in NSCLC}

Preclinical studies have shown that activation of the EGFR pathway can upregulate the expression of PD-1, PD-L1, and CTLA-4 through p-ERK1/2p-c-Jun, leading to the apoptosis of $\mathrm{T}$ cells in tumor microenvironment; this mediates the escape of tumor cells from the host immune response, leading to a state of immunosuppression. ${ }^{39-41}$ Using a murine model, Akbay et $\mathrm{al}^{39}$ found that PD-1 expression was upregulated in an EGFR-mutant cell line, while anti-PD-1 treatment resulted in a reduced tumor mass and prolonged mouse survival. Azuma et $\mathrm{al}^{42}$ used immunohistochemistry to analyze the expression of PD-L1 in 164 surgically resected NSCLC specimens, and multivariate analysis showed that EGFR mutations and adenocarcinoma were independent factors contributing to the increase of PD-L1 expression. 
Table I Preclinical studies of immune checkpoint inhibitors in combination with EGFR-TKIs in advanced NSCLC

\begin{tabular}{|c|c|c|}
\hline Author & Model & Results \\
\hline Akbay et $\mathrm{al}^{39}$ & $\begin{array}{l}\text { NSCLC cell line with } \\
\text { activated EGFR; murine }\end{array}$ & $\begin{array}{l}\text { EGFR-mutant cell lines can upregulate the PD-I expression; PD-LI } \\
\text { expression was reduced by EGFR inhibitors. }\end{array}$ \\
\hline Chen et al ${ }^{40}$ & NSCLC cell lines & $\begin{array}{l}\text { EGFR activation upregulated PD-LI through p-ERKI/2/p-c-Jun; } \\
\text { EGFR-TKIs can downregulate PD-LI. }\end{array}$ \\
\hline Azuma et $\mathrm{al}^{42}$ & $\begin{array}{l}\text { NSCLC cell lines; surgically } \\
\text { resected NSCLC specimens }\end{array}$ & $\begin{array}{l}\text { High expression of PD-LI was associated with EGFR mutations; EGFR } \\
\text { inhibitor erlotinib downregulated PD-LI expression. }\end{array}$ \\
\hline Lin et $\mathrm{al}^{43}$ & NSCLC cell lines; murine & $\begin{array}{l}\text { EGFR mutation expresses higher PD-LI than wild-type EGFR; EGFR } \\
\text { activation is associated with high expression of PD-LI. The EGFR-TKI } \\
\text { gefitinib can reduce PD-LI expression via inhibiting NF-KB. }\end{array}$ \\
\hline He et $\mathrm{al}^{44}$ & NSCLC cell lines & $\begin{array}{l}\text { EGFR-TKI gefitinib could block the immune escape by upregulating the } \\
\text { expression of NKG2D ligands on tumor cells and NKG2D on NK cells. }\end{array}$ \\
\hline Kim et $\mathrm{a}^{45}$ & NSCLC cell lines & $\begin{array}{l}\text { EGFR inhibitors enhanced the susceptibility to NK cell-mediated lysis } \\
\text { by induction of ULBPI by inhibition of PKC pathway. }\end{array}$ \\
\hline
\end{tabular}

Abbreviations: NF-KB, nuclear factor-kappa B; NSLC, non-small-cell lung cancer; PD-I, programmed death-I; PD-LI, programmed death-ligand I; PKC, protein kinase C; TKI, tyrosine kinase inhibitor; EGFR, epidermal growth factor receptor.

EGFR-TKIs not only target and kill the tumor directly but can also enhance the immune system response. Treatment of EGFR-mutant NSCLC cell lines with EGFR-TKIs reduced the expression of PD-1 and PD-L1 by inhibiting nuclear factor-kappa B (NF- $\mathrm{KB})$ signaling. ${ }^{39,42,43}$ In addition, the EGFR inhibitor gefitinib enhanced the antigenicity of in vitro-cultured human or mouse cancer cells by restoring major histocompatibility class 1 expression, and both gefitinib and erlotinib promoted the recognition and elimination of tumors by natural killer cells stimulated by NKG2D ligand in vitro or in immunocompetent host cancer cells. ${ }^{44,45}$ Table 1 summarizes the preclinical studies of the use of EGFR-TKIs plus immunotherapy in NSCLC.

These studies provide a theoretical basis for treatment using EGFR-TKIs in combination with immunotherapy in order to improve clinical outcomes in patients with NSCLC tumors harboring EGFR mutations, accompanied by upregulation of PD-L1 expression. ${ }^{46}$

\section{Clinical trials of EGFR-TKIs plus immunotherapy in NSCLC}

Despite the potential of EGFR-TKIs and immunotherapy to suppress tumor growth and improve survival in vitro or in animal models, in practice, EGFR-mutant NSCLC is often associated with a lack of tumor-infiltrating lymphocytes; ${ }^{47}$ therefore, clinical trials have begun to examine the combined effects of EGFR-TKIs and an immunosuppressive agent; these are summarized in Table 2.

The randomized Phase III clinical study, OAK, analyzed 1,225 patients with locally advanced or metastatic NSCLC who had failed platinum-based chemotherapy. The primary efficacy analysis included the first 850 of these
1,225 enrolled patients. The patients were randomly assigned $(1: 1)$ to receive either atezolizumab $1,200 \mathrm{mg}(\mathrm{n}=425)$ or docetaxel $75 \mathrm{mg} / \mathrm{m}^{2}(\mathrm{n}=425)$ intravenously every 3 weeks. The primary endpoint was OS in the intention-to-treat and PD-L1 expression population $\mathrm{TC} 1 / 2 / 3$ or $\mathrm{IC} 1 / 2 / 3$ ( $\geq 1 \%$ PD-L1 on tumor cells or tumor-infiltrating immune cells). The results showed that in the intention-to-treat population, the OS of patients treated with atezolizumab was significantly longer than that of those receiving docetaxel (13.8 vs 9.6 months, HR 0.73 [ $95 \%$ CI, 0.62-0.87], $P=0.0003$ ). In the TC1/2/3 or IC1/2/3 population, OS was also longer with atezolizumab $(n=241)$ than that with docetaxel $(n=222 ; 15.7$ vs 10.3 months; HR 0.74 [95\% CI, 0.58-0.93]; $P=0.0102){ }^{48}$

A meta-analysis of three clinical trials (CheckMate 057, KEYNOTE-010, and POPLAR studies) investigating combined immunotherapy and chemotherapy for patients with advanced NSCLC, including patients with EGFR-mutated NSCLC treated with EGFR-TKI-targeted therapy, showed that patients with EGFR mutations did not obtain a survival benefit from treatment with a PD-1/PD-L1 monoclonal antibody compared with those treated with docetaxel. ${ }^{49}$

A Phase I clinical trial (NCT02013219) reported the preliminary results of erlotinib plus atezolizumab treatment in patients with NSCLC. The safety phase included patients with locally advanced or metastatic NSCLC, and the extension phase included patients with EGFR mutations who did not receive TKIs. Toward the end of the trial, 28 patients (eight in the safety phase and 20 in the extension phase) were evaluated for safety and efficacy. This study found that $39 \%$ of the patients had grade 3-4 adverse reactions, mainly fever and elevated alanine aminotransferase levels, although there were no reports of interstitial pneumonia interstitial lung disease. 
Table 2 Clinical trials of immune checkpoint inhibitors in combination with EGFR-TKIs in advanced NSCLC

\begin{tabular}{|c|c|c|c|c|c|}
\hline Clinical trial & Patients & Targeted agent & Immunotherapy & Phase & Status \\
\hline NCT02088II 2 & LA/stage IV TKI-naïve EGFR-mutated NSCLC & Gefitinib & Durvalumab & 1 & $\begin{array}{l}\text { Active, not } \\
\text { recruiting }\end{array}$ \\
\hline NCT02040064/GEFTREM & LA/stage IV TKI-pretreated EGFR-mutated NSCLC & Gefitinib & Tremelimumab & 1 & Completed \\
\hline NCT02574078/CheckMate 370 & Newly diagnosed/maintenance LA/stage IV NSCLC & Erlotinib & Nivolumab & $\mathrm{I} / \mathrm{II}$ & $\begin{array}{l}\text { Active, not } \\
\text { recruiting }\end{array}$ \\
\hline NCT0I998I26 & $\begin{array}{l}\text { Stages II-IV TKI-naïe or TKI treated } \\
\text { for }<6 \text { months EGFR- or ALK-mutated NSCLC }\end{array}$ & Erlotinib & $\begin{array}{l}\text { Nivolumab/ } \\
\text { ipilimumab }\end{array}$ & 1 & Completed \\
\hline NCT0I454I02/CheckMate 012 & $\begin{array}{l}\text { Newly diagnosed or pretreated stage IIIB/IV } \\
\text { NSCLC }\end{array}$ & Erlotinib & Nivolumab & 1 & $\begin{array}{l}\text { Active, not } \\
\text { recruiting }\end{array}$ \\
\hline NCT020I3219 & $\begin{array}{l}\text { LA/stage IV TKI-naïve EGFR-mutated and } \\
\text { treatment-naïve ALK-positive NSCLC }\end{array}$ & Erlotinib & Atezolizumab & 1 & $\begin{array}{l}\text { Active, not } \\
\text { recruiting }\end{array}$ \\
\hline NCT02039674/KEYNOTE-02I & $\begin{array}{l}\text { Newly diagnosed stage IIIB/IV NSCLC, } \\
\text { progression }>\text { I year after adjuvant therapy for } \\
\text { stages I-IIIA NSCLC }\end{array}$ & Erlotinib/gefitinib & Pembrolizumab & $\mathrm{I} / \mathrm{II}$ & $\begin{array}{l}\text { Active, not } \\
\text { recruiting }\end{array}$ \\
\hline NCT02630I86 & $\begin{array}{l}\text { Patients with activating EGFR mutation-positive } \\
\text { (EGFRm) advanced or metastatic NSCLC }\end{array}$ & Rociletinib & Atezolizumab & $1 / I I$ & $\begin{array}{l}\text { Active, not } \\
\text { recruiting }\end{array}$ \\
\hline NCT03I57089/LUX-Lung IO & Pretreated stage IIIB/IV squamous NSCLC & Afatinib & Pembrolizumab & II & Recruiting \\
\hline NCT02364609 & $\begin{array}{l}\text { LA/stage IV/recurrent erlotinib-resistant } \\
\text { EGFR-mutated NSCLC }\end{array}$ & Afatinib & Pembrolizumab & I & Recruiting \\
\hline NCT02I43466 & $\begin{array}{l}\text { EGFRm+advanced NSCLC who have progressed } \\
\text { following therapy with an EGFR-TKI }\end{array}$ & Osimertinib & Durvalumab & 1 & Terminated $^{\mathrm{a}}$ \\
\hline
\end{tabular}

Note: a Due to an increased incidence of interstitial pneumonia-like events (interstitial lung disease/pneumonitis).

Abbreviations: ALK, anaplastic lymphoma kinase; LA, locally advanced; NSCLC, non-small-cell lung cancer; TKI, tyrosine kinase inhibitor; EGFR, epidermal growth factor receptor.

In terms of clinical efficacy, the objective response rate (ORR) reached $75 \%$ with a median duration of 9.7 months. This trial showed that combination therapy can lead to a significant increase in adverse reactions in the absence of substantial improvements in ORR or OS. ${ }^{50}$ Another Phase I clinical trial (NCT02088112) evaluated the treatment of patients with NSCLC using gefitinib and durvalumab. By the end of the trial, 20 EGFR-TKI-naive patients with EGFRmutant NSCLC were included in the expansion phase; half of these received both durvalumab $(10 \mathrm{mg} / \mathrm{kg}$ once every 2 weeks) and gefitinib ( $250 \mathrm{mg} /$ day) (group 1), while the other half received gefitinib monotherapy for 28 days, followed by combined gefitinib and durvalumab treatment (group 2). Due to extensive grade 3-4 adverse reactions, four patients in group 2 discontinued treatment; three patients had elevated activities of alanine aminotransferase/aspartate aminotransferase and one patient developed ILD. In terms of clinical efficacy, the ORRs of patients in groups 1 and 2 were $77.8 \%$ and $80 \%$, respectively. ${ }^{51}$ As part of the CheckMate 012 study, the efficacy of erlotinib combined with nivolumab was evaluated in 21 patients with EGFR-mutated NSCLC; 20 patients received erlotinib and one patient did not receive EGFR-TKI therapy. ${ }^{52}$ The treatment regimen was nivolumab $(3 \mathrm{mg} / \mathrm{kg}$, once every 2 weeks)+erlotinib (150 mg, once a day) until disease progression or intolerable toxicity occurred. The most common side effects included rash, fatigue, paronychia, diarrhea, and cracked skin. Grade 3 toxicity occurred in 19\% of patients, but no grade 4 toxicity was reported. In terms of clinical efficacy, the ORR was $19 \%$, PFS was $51 \%$ at 24 weeks, and OS was $64 \%$ at 18 months. In addition, three of the 20 patients treated with EGFR-TKIs achieved partial remission, with a median time to remission of 60.1 weeks. Two repeat biopsies of patients with T790M-negative tumors showed a PFS of 61 weeks and $\geq 108$ weeks. One patient who had not received treatment with EGFR-TKIs reached partial remission at the time of the report and continued the treatment for 72.3 weeks. Owing to treatment-related adverse events (grade 3 aspartate aminotransferase elevation and grade 2 nephritis), two patients discontinued the treatment.

The Phase Ib TATTON study evaluated combination treatments with osimertinib and MEDI4736, AZD6094, or selumetinib in EGFR active mutant lung cancer and also determined the efficacy of axitinib in combination with the anti-PD-L1 antibody durvalumab. ${ }^{53} \mathrm{~A}$ total of 34 patients were assigned to the EGFR-TKI-treated group (23 cases, increasing dose phase, group A) and EGFR-TKI initial treatment group (11 cases, extended phase, group B). The treatment regimen was osimertinib ( $80 \mathrm{mg}$ once a day)+durvalumab (3 mg/kg or $10 \mathrm{mg} / \mathrm{kg}$ once every 2 weeks). The ORR for T790M-positive and T790M-negative patients treated with EGFR-TKIs was $67 \%$ and $21 \%$, respectively, 
whereas that for patients who did not receive EGFR-TKIs was $70 \%$. However, this combination therapy was associated with a high incidence of ILD, which occurred in $38 \%$ $(13 / 34)$ of patients overall (26\% [6/23] in group A and 64\% $[7 / 11]$ in group B). In contrast, the incidence of ILD associated with osimertinib and durvalumab was only $2 \%-3 \%$ and $<2 \%$, respectively. The median time for ILD to occur was 69 days. Five of the 13 patients who developed ILD had grade $3 / 4$, but there were no deaths, and most were alleviated using high-dose corticosteroids and discontinuation of the target drug. Because the underlying mechanisms associated with this high incidence of ILD remain unknown, recruitment has stopped for this arm of this trial. Similarly, a Phase III clinical trial CAUREL (NCT02454933) assessing the effects of durvalumab in combination with osimertinib or osimertinib alone in T790M-positive NSCLC patients after treatment with EGFR-TKIs has also been suspended. Oshima et al analyzed the incidence of EGFR-TKI-associated interstitial pneumonitis (IP) in patients receiving or not receiving nivolumab treatment. ${ }^{54}$ The results showed that the incidence of IP was $4.8 \%(985 / 20,516)$ in all the patients, with incidences of $4.59 \%(265 / 5,777)$ and $25.7 \%(18 / 70)$ in those treated with EGFR-TKI or both EGFR-TKI and nivolumab, respectively. The adjusted odds ratio for an interaction between EGFR-TKI and nivolumab was 4.31 (95\% CI, 2.37-7.86; $P<0.001$ ), suggesting a higher proportion of reports of IP for nivolumab in combination with EGFR-TKI vs treatment with either drug alone. Haratani et al reported the results of a study of 25 patients with EGFR mutationpositive NSCLC who were treated with nivolumab after progressing to EGFR-TKIs. ${ }^{55}$ The T790M-negative patients had a longer PFS (2.1 months) than the T790M-positive patients (1.3 months) and also had a higher proportion of tumors with a PD-L1 level of $\geq 10 \%$ or $\geq 50 \%$ than that of the T790M-positive patients, along with higher CD8 $8^{+}$tumor infiltration and a greater tumor mutation load.

\section{Potential factors affecting the success of combined EGFR-TKIs and immunotherapy}

The clinical studies conducted to date have shown that the combination of EGFR-TKIs with immunity checkpoint inhibitors does not have a synergistic tumor cell-killing effect. The tumor mutation load, epithelial-mesenchymal transition, and transforming growth factor- $\beta$ all affect tumor immunogenicity. ${ }^{56-58}$ Moreover, PD-L1 expression alone does not accurately predict the prognosis of PD-1/PD-L1 monoclonal antibody therapy in patients with NSCLC.
Prognosis is also associated with smoking history and the tumor mutation burden. ${ }^{56,59-65}$ Because the incidence of tumor mutation in smokers is 10 times higher than in nonsmokers, smoking history is strongly related to the clinical prognosis of NSCLC immunotherapy. ${ }^{66}$ However, most patients carrying $E G F R$ gene mutations are those that smoked mildly or are nonsmokers, with a low tumor mutation burden. Exome sequencing analysis showed that EGFR-mutated NSCLC patients had a low mutation load, which may lead to a low RR to immunotherapy. ${ }^{56,65-69}$ Moreover, only a small proportion of patients with EGFR mutation and ALK rearrangement have both positive PD-L1 expression and high levels of CD8 ${ }^{+}$ tumor-infiltrating lymphocytes, suggesting that the lack of an inflammatory microenvironment may limit the efficacy of PD-1/PD-L1 monoclonal antibodies. ${ }^{67,70}$

PD-L1 can be induced by oncogenic signals and can also be upregulated by interferon-gamma (INFG) in a STAT-1 and NF- $\kappa \mathrm{B}$-dependent manner. A recent study evaluating INFG levels in pretreatment tumor samples from patients with advanced NSCLC showed that intermediate and high levels of INFG microRNA expression correlated with longer PFS and OS and higher disease control rates with PD-1 monoclonal antibody treatment, even when PD-L1 expression was low. In contrast, low levels of INFG were correlated with poor prognosis. ${ }^{71}$ Another study showed that in EGFR-mutant tumor samples, overexpression of the immunosuppressive molecule CD73 was associated with low INFG expression, which may be associated with the poor therapeutic efficacy of PD-1/PD-L1 antibodies in this group of patients. ${ }^{72}$ Overall, EGFR-mutant NSCLC-mediated immune escape appears to mainly occur by upregulating PD-L1 expression; thus, EGFR-TKIs and PD-1 monoclonal antibodies may have similar but not synergistic effects in targeting this mechanism. ${ }^{40}$

\section{Conclusion and future prospects}

This review summarizes the potential benefits and problems associated with the combined use of EGFR-TKIs and immunotherapy in patients with NSCLC. In preclinical studies, EGFR signaling pathways induced the expression of PD-L1 and other immunosuppressive factors, suggesting that EGFR oncogenes effectively remodel the immune microenvironment. Several early clinical studies have also confirmed the efficacy of immunotherapy in patients with EGFR-mutant NSCLC; however, grade 3-4 adverse events such as elevated ILD incidence and alanine aminotransferase/aspartate aminotransferase levels resulted in treatment failure. Several large randomized Phase III clinical trials have not demonstrated 
a clinical benefit of PD-1/PD-L1 monoclonal antibodies in patients with EGFR-mutant NSCLC; this may be due to a lower tumor mutation burden, fewer $\mathrm{CD}^{+}$tumor-infiltrating cells, and lower expression of INFG in these cases.

Nanotechnology is a comprehensive platform that has the potential to significantly improve cancer diagnosis and treatment while reducing toxicity. Nanoparticles, which are generally derived from polymers, lipids, or metals, can be coupled with a therapeutic drug and used to target tumors by exploiting their biophysical differences from normal tissue; these include hypoxia and an acidic $\mathrm{pH}$. Nanoparticles can also incorporate specific targeting ligands designed to bind with receptors that are overexpressed by tumor cells or stromal cells, facilitating drug delivery and release at the site of action. ${ }^{73}$ Therefore, nanomedicines provide high levels of control, biocompatibility, versatility, and surface area to volume ratios ${ }^{74,75}$ they provide opportunities to target tumors, to release the drug cargo specifically in the tumor microenvironment, and to increase the drug circulation halflife. ${ }^{76-79}$ Wang et al also discussed the use of nanomaterials as gene delivery systems. ${ }^{80}$ In addition, nanomaterials can be designed to provide more complex therapeutic agents, such as codelivery of antitumor drugs with antiangiogenic antibodies or peptides, or other immunotherapeutic antibodies. ${ }^{81-85}$ Therefore, the treatment of patients with NSCLC may be further improved by coupling commonly used EGFR-TKIs and immunity checkpoint inhibitors to nanoparticles.

Research relating to the use of EGFR-TKIs combined with immunotherapy in the treatment of NSCLC is still at an early stage. Thus, further efforts are needed to assess the different drugs, dosages, administration sequences, and side effects associated with this type of combination therapy.

\section{Disclosure}

The authors report no conflicts of interest in this work.

\section{References}

1. Siegel RL, Miller KD, Jemal A. Cancer statistics, 2017. CA Cancer J Clin. 2017;67(1):7-30.

2. Huang S-M, Harari PM. Epidermal growth factor receptor inhibition in cancer therapy: biology, rationale and preliminary clinical results. Invest New Drugs. 1999;17(3):259-269.

3. Dutta PR, Maity A. Cellular responses to EGFR inhibitors and their relevance to cancer therapy. Cancer Lett. 2007;254(2):165-177.

4. Grandis JR, Sok JC. Signaling through the epidermal growth factor receptor during the development of malignancy. Pharmacol Ther. 2004; 102(1):37-46.

5. Yarden Y, Pines G. The ERBB network: at last, cancer therapy meets systems biology. Nat Rev Cancer. 2012;12(8):553-563.

6. Jaiswal BS, Kljavin NM, Stawiski EW, et al. Oncogenic ERBB3 mutations in human cancers. Cancer Cell. 2013;23(5):603-617.

7. Yarden Y, Sliwkowski MX. Untangling the ErbB signalling network. Nat Rev Mol Cell Biol. 2001;2(2):127-137.
8. Paez JG, Jänne PA, Lee JC, et al. EGFR mutations in lung cancer: correlation with clinical response to gefitinib therapy. Science. 2004; 304(5676): 1497-1500.

9. Lynch TJ, Bell DW, Sordella R, et al. Activating mutations in the epidermal growth factor receptor underlying responsiveness of non-small-cell lung cancer to gefitinib. $N$ Engl J Med. 2004;350(21):2129-2139.

10. Ekstrand AJ, Longo N, Hamid ML, et al. Functional characterization of an EGF receptor with a truncated extracellular domain expressed in glioblastomas with EGFR gene amplification. Oncogene. 1994;9(8): 2313-2320.

11. Rosell R, Carcereny E, Gervais R, et al. Erlotinib versus standard chemotherapy as first-line treatment for European patients with advanced EGFR mutation-positive non-small-cell lung cancer (EURTAC): a multicentre, open-label, randomised phase 3 trial. Lancet Oncol. 2012; 13(3):239-246.

12. Maemondo M, Inoue A, Kobayashi K, et al. Gefitinib or chemotherapy for non-small-cell lung cancer with mutated EGFR. NEngl J Med. 2010; 362(25):2380-2388.

13. Sequist LV, Yang JC-H, Yamamoto N, et al. Phase III study of afatinib or cisplatin plus pemetrexed in patients with metastatic lung adenocarcinoma with EGFR mutations. J Clin Oncol. 2013;31(27):3327-3334.

14. Paz-Ares L, Tan E-H, O'Byrne K, et al. Afatinib versus gefitinib in patients with EGFR mutation-positive advanced non-small-cell lung cancer: overall survival data from the phase IIb LUX-Lung 7 trial. Ann Oncol. 2017;28(2):270-277.

15. Mok T, Cheng Y, Zhou X, et al. Dacomitinib versus gefitinib for the first-line treatment of advanced EGFR mutation positive non-small cell lung cancer (ARCHER 1050): a randomized, open-label phase III trial. J Clin Oncol. 2017;35(18 Suppl):LBA9007.

16. Solomon BJ, Mok T, Kim D-W, et al. First-line crizotinib versus chemotherapy in ALK-positive lung cancer. N Engl J Med. 2014;371(23): 2167-2177.

17. Peters S, Camidge DR, Shaw AT, et al. Alectinib versus crizotinib in untreated $A L K$-positive non-small-cell lung cancer. NEngl J Med. 2017; 377(9):829-838.

18. Shaw AT, Kim TM, Crinò L, et al. Ceritinib versus chemotherapy in patients with ALK-rearranged non-small-cell lung cancer previously given chemotherapy and crizotinib (ASCEND-5): a randomised, controlled, open-label, phase 3 trial. Lancet Oncol. 2017;18(7):874-886.

19. Kim D-W, Tiseo M, Ahn M-J, et al. Brigatinib in patients with crizotinibrefractory anaplastic lymphoma kinase-positive non-small-cell lung cancer: a randomized, multicenter phase II trial. J Clin Oncol. 2017; 35(22):2490-2498.

20. Shaw AT, Bauer TM, Felip E. Clinical activity and safety of PF-06463922 from a dose escalation study in patients with advanced ALK+ or ROS1+NSCLC. J Clin Oncol. 2015;33(15 Suppl):8018.

21. Shaw AT, Ou S-HI, Bang Y-J, et al. Crizotinib in ROS1-rearranged non-small-cell lung cancer. N Engl J Med. 2014;371(21):1963-1971.

22. Santarpia M, Gil N, Rosell R. Strategies to overcome resistance to tyrosine kinase inhibitors in non-small-cell lung cancer. Expert Rev Clin Pharmacol. 2015;8(4):461-477.

23. Mok TS, Wu Y-L, Ahn M-J, et al. Osimertinib or platinum-pemetrexed in EGFR T790M-positive lung cancer. N Engl J Med. 2017;376(7): 629-640.

24. Ou Q, Wu X, Bao H, et al. Investigating novel resistance mechanisms to third generation EGFR TKI osimertinib in non-small cell lung cancer patients using next generation sequencing. J Clin Oncol. 2017;35:2572.

25. Mok TS, Cheng Y, Zhou X, et al. Improvement in overall survival in a randomized study that compared dacomitinib with gefitinib in patients with advanced non-small-cell lung cancer and EGFR-activating mutations. J Clin Oncol. 2018;36(22):2244-2250.

26. Yu HA, Arcila ME, Rekhtman N, et al. Analysis of tumor specimens at the time of acquired resistance to EGFR-TKI therapy in 155 patients with EGFR-mutant lung cancers. Clin Cancer Res. 2013;19(8): 2240-2247.

27. Jänne PA, Yang JC-H, Kim D-W, et al. AZD9291 in EGFR inhibitorresistant non-small-cell lung cancer. $N$ Engl J Med. 2015;372(18): $1689-1699$. 
28. Thress KS, Paweletz CP, Felip E, et al. Acquired EGFR C797S mutation mediates resistance to AZD9291 in non-small cell lung cancer harboring EGFR T790M. Nat Med. 2015;21(6):560-562.

29. Šmahel M. PD-1/PD-L1 blockade therapy for tumors with downregulated MHC class I expression. Int J Mol Sci. 2017;18(6):1331.

30. Gong J, Chehrazi-Raffle A, Reddi S, Salgia R. Development of PD-1 and PD-L1 inhibitors as a form of cancer immunotherapy: a comprehensive review of registration trials and future considerations. $J$ Immunother Cancer. 2018;6(1):8.

31. Reck M, Rodríguez-Abreu D, Robinson AG, et al. Pembrolizumab versus chemotherapy for PD-L1-positive non-small-cell lung cancer. N Engl J Med. 2016;375(19):1823-1833.

32. Borghaei H, Paz-Ares L, Horn L, et al. Nivolumab versus docetaxel in advanced nonsquamous non-small-cell lung cancer. NEngl JMed. 2015 373(17):1627-1639.

33. Brahmer J, Reckamp KL, Baas P, et al. Nivolumab versus docetaxel in advanced squamous-cell non-small-cell lung cancer. $N$ Engl J Med Overseas Ed. 2015;373(2):123-135.

34. Herbst RS, Baas P, Kim D-W, et al. Pembrolizumab versus docetaxel for previously treated, PD-L1-positive, advanced non-small-cell lung cancer (KEYNOTE-010): a randomised controlled trial. Lancet. 2016; 387(10027):1540-1550.

35. Rittmeyer A, Barlesi F, Waterkamp D, et al. Atezolizumab versus docetaxel in patients with previously treated non-small-cell lung cancer (OAK): a phase 3, open-label, multicentre randomised controlled trial. Lancet. 2017;389(10066):255-265.

36. Langer CJ, Gadgeel SM, Borghaei H, et al. Carboplatin and pemetrexed with or without pembrolizumab for advanced, non-squamous nonsmall-cell lung cancer: a randomised, phase 2 cohort of the open-label KEYNOTE-021 study. Lancet Oncol. 2016;17(11):1497-1508.

37. Abril-Rodriguez G, Ribas A. SnapShot: immune checkpoint inhibitors. Cancer Cell. 2017;31(6):848.

38. Pilotto S, Molina-Vila MA, Karachaliou N, et al. Integrating the molecular background of targeted therapy and immunotherapy in lung cancer: a way to explore the impact of mutational landscape on tumor immunogenicity. Transl Lung Cancer Res. 2015;4(6):721-727.

39. Akbay EA, Koyama S, Carretero J, et al. Activation of the PD-1 pathway contributes to immune escape in EGFR-driven lung tumors. Cancer Discov. 2013;3(12):1355-1363.

40. Chen N, Fang W, Zhan J, et al. Upregulation of PD-L1 by EGFR activation mediates the immune escape in EGFR-driven NSCLC: implication for optional immune targeted therapy for NSCLC patients with EGFR mutation. J Thorac Oncol. 2015;10(6):910-923.

41. Ota K, Azuma K, Kawahara A, et al. Induction of PD-L1 expression by the EML4-ALK oncoprotein and downstream signaling pathways in nonsmall cell lung cancer. Clin Cancer Res. 2015;21(17):4014-4021.

42. Azuma K, Ota K, Kawahara A, et al. Association of PD-L1 overexpression with activating EGFR mutations in surgically resected nonsmallcell lung cancer. Ann Oncol. 2014;25(10):1935-1940.

43. Lin K, Cheng J, Yang T, Li Y, Zhu B. EGFR-TKI down-regulates PD-L1 in EGFR mutant NSCLC through inhibiting NF- $\kappa$ B. Biochem Biophys Res Commun. 2015;463(1-2):95-101.

44. He S, Yin T, Li D, et al. Enhanced interaction between natural killer cells and lung cancer cells: involvement in gefitinib-mediated immunoregulation. J Transl Med. 2013;11:186.

45. Kim H, Kim S-H, Kim M-J, et al. EGFR inhibitors enhanced the susceptibility to NK cell-mediated lysis of lung cancer cells. J Immunother. 2011;34(4):372-381.

46. D'Incecco A, Andreozzi M, Ludovini V, et al. PD-1 and PD-L1 expression in molecularly selected non-small-cell lung cancer patients. Br J Cancer. 2015;112(1):95-102.

47. Rutledge WC, Kong J, Gao J, et al. Tumor-infiltrating lymphocytes in glioblastoma are associated with specific genomic alterations and related to transcriptional class. Clin Cancer Res. 2013;19(18):4951-4960.

48. Rittmeyer A, Barlesi F, Waterkamp D, et al. Atezolizumab versus docetaxel in patients with previously treated non-small-cell lung cancer (OAK): a phase 3, open-label, multicentre randomised controlled trial. Lancet. 2017;389(10066):255-265.
49. Lee CK, Man J, Lord S, et al. Checkpoint inhibitors in metastatic EGFRmutated non-small cell lung cancer - a meta-analysis. J Thorac Oncol. 2017;12(2):403-407.

50. Ma BBY, Rudin CM, Cervantes A, et al. Preliminary safety and clinical activity of erlotinib plus atezolizumab from a Phase Ib study in advanced NSCLC. Ann Oncol. 2016;27(9 Suppl):mdw594.005.

51. Gibbons DL, Chow LQ, Kim D-W, et al. 57O Efficacy, safety and tolerability of MEDI4736 (durvalumab [D]), a human IgG1 antiprogrammed cell death-ligand-1 (PD-L1) antibody, combined with gefitinib (G): a phase I expansion in TKI-naïve patients (pts) with EGFR mutant NSCLC. J Thorac Oncol. 2016;11(4):S79.

52. Antonia SJ, Rizvi NA, Chow LQ, et al. Nivolumab (Anti-Pd-1; Bms-936558, Ono-4538) in combination with platinum-based doublet chemotherapy (Pt-Dc) or erlotinib in advanced non-small cell lung cancer (NSCLC). J Thorac Oncol. 2014;9(9):S153-S153.

53. Ahn M-J, Yang J, Yu H, et al. 136O: Osimertinib combined with durvalumab in EGFR-mutant non-small cell lung cancer: results from the TATTON phase Ib trial. J Thorac Oncol. 2016;11(4):S115.

54. Oshima Y, Tanimoto T, Yuji K, Tojo A. EGFR-TKI-associated interstitial pneumonitis in nivolumab-treated patients with non-small cell lung cancer. JAMA Oncol. 2018;4(8):1112-1115.

55. Haratani K, Hayashi H, Tanaka T, et al. Tumor immune microenvironment and nivolumab efficacy in EGFR mutation-positive non-small-cell lung cancer based on T790M status after disease progression during EGFR-TKI treatment. Ann Oncol. 2017;28(7):1532-1539.

56. Rizvi NA, Hellmann MD, Snyder A, et al. Mutational landscape determines sensitivity to PD-1 blockade in non-small cell lung cancer. Science. 2015;348(6230):124-128.

57. Santarpia M, González-Cao M, Viteri S, Karachaliou N, Altavilla G, Rosell R. Programmed cell death protein-1/programmed cell death ligand-1 pathway inhibition and predictive biomarkers: understanding transforming growth factor-beta role. Transl Lung Cancer Res. 2015;4(6): $728-742$.

58. Lou YY, Diao LZ, Byers LA. Association of epithelial-mesenchymal transition status with PD1/PDL1 expression and a distinct immunophenotype in non small cell lung cancer: Implications for immunotherapy biomarkers. J Clin Oncol. 2014;32(15 Suppl):3018.

59. Han JJ, Kim D-W, Koh J, et al. Change in PD-L1 expression after acquiring resistance to gefitinib in EGFR-mutant non-small-cell lung cancer. Clin Lung Cancer. 2016;17(4):263-270.

60. Zhou GW, Xiong Y, Chen S, Xia F, Li Q, Hu J. Anti-PD-1/PD-L1 antibody therapy for pretreated advanced nonsmall-cell lung cancer: a metaanalysis of randomized clinical trials. Medicine. 2016;95(35):e4611.

61. Chae YK, Pan A, Davis AA, et al. Biomarkers for PD-1/PD-L1 blockade therapy in non-small-cell lung cancer: is PD-L1 expression a good marker for patient selection? Clin Lung Cancer. 2016;17(5): $350-361$.

62. Jing W, Li M, Zhang Y, et al. PD-1/PD-L1 blockades in non-small-cell lung cancer therapy. Onco Targets Ther. 2016;9:489-502.

63. Shien K, Papadimitrakopoulou VA, Wistuba II. Predictive biomarkers of response to PD-1/PD-L1 immune checkpoint inhibitors in non-small cell lung cancer. Lung Cancer. 2016;99:79-87.

64. Yang Y, Pang Z, Ding N, et al. The efficacy and potential predictive factors of PD-1/PD-L1 blockades in epithelial carcinoma patients: a systematic review and meta analysis. Oncotarget. 2016;7(45): $74350-74361$.

65. Grigg C, Rizvi NA. PD-L1 biomarker testing for non-small cell lung cancer: truth or fiction? J Immunother Cancer. 2016;4(1):48.

66. Govindan R, Ding L, Griffith M, et al. Genomic landscape of non-small cell lung cancer in smokers and never-smokers. Cell. 2012;150(6): 1121-1134.

67. Gainor JF, Sequist LV, Shaw AT. Clinical correlation and frequency of programmed death ligand-1 (PD-L1) expression in EGFR-mutant and ALK-rearranged non-small cell lung cancer (NSCLC).JClin Oncol.2015; 33(15):8012.

68. Cancer Genome Atlas Research Network. Comprehensive molecular profiling of lung adenocarcinoma. Nature. 2014;511(7511): $543-550$. 
69. Spigel DR, Schrock AB, Fabrizio D, et al. Total mutation burden (TMB) in lung cancer (LC) and relationship with response to PD-1/PD-L1 targeted therapies. J Clin Oncol. 2016;34(15):9017.

70. Gainor JF, Shaw AT, Sequist LV, et al. EGFR mutations and ALK rearrangements are associated with low response rates to PD-1 pathway blockade in non-small cell lung cancer: a retrospective analysis. Clin Cancer Res. 2016;22(18):4585-4593.

71. Karachaliou N, Crespo G, Aldeguer E. Interferon-gamma (INFG), an important marker of response to immune checkpoint blockade (ICB) in non-small cell lung cancer (NSCLC) and melanoma patients. J Clin Oncol. 2017;35(15 Suppl):11504.

72. Streicher K, Higgs BW, Wu S, et al. Increased CD73 and reduced IFNG signature expression in relation to response rates to anti-PD-1(L1) therapies in EGFR-mutant NSCLC. J Clin Oncol. 2017;35(15 Suppl): 11505.

73. Chow EK-H, Ho D. Cancer nanomedicine: from drug delivery to imaging. Sci Transl Med. 2013;5(216):216rv4.

74. Ryou S-M, Kim S, Jang HH, et al. Delivery of shRNA using gold nanoparticle-DNA oligonucleotide conjugates as a universal carrier. Biochem Biophys Res Commun. 2010;398(3):542-546.

75. Sokolova V, Epple M. Inorganic nanoparticles as carriers of nucleic acids into cells. Angew Chemie Int Edit. 2008;47(8):1382-1395.

76. Aluri S, Janib SM, Mackay JA. Environmentally responsive peptides as anticancer drug carriers. Adv Drug Deliv Rev. 2009;61(11):940-952.

77. Danhier F, Feron O, Préat V. To exploit the tumor microenvironment: passive and active tumor targeting of nanocarriers for anti-cancer drug delivery. J Control Release. 2010;148(2):135-146.
78. Kievit FM, Zhang M. Cancer nanotheranostics: improving imaging and therapy by targeted delivery across biological barriers. Adv Mater. 2011;23(36):H217-H247.

79. Schroeder A, Heller DA, Winslow MM, et al. Treating metastatic cancer with nanotechnology. Nat Rev Cancer. 2012;12(1):39-50.

80. Wang K, Huang Q, Qiu F, Sui M. Non-viral delivery systems for the application in p53 cancer gene therapy. Curr Med Chem. 2015; 22(35):4118-4136.

81. Hatakeyama H, Akita H, Ishida E, et al. Tumor targeting of doxorubicin by anti-MT1-MMP antibody-modified PEG liposomes. Int J Pharm. 2007;342(1-2):194-200.

82. Pastorino F, Brignole C, di Paolo D, et al. Targeting liposomal chemotherapy via both tumor cell-specific and tumor vasculature-specific ligands potentiates therapeutic efficacy. Cancer Res. 2006;66(20): 10073-10082.

83. Pastorino F, Brignole C, Marimpietri D, et al. Vascular damage and antiangiogenic effects of tumor vessel-targeted liposomal chemotherapy. Cancer Res. 2003;63(21):7400-7409.

84. Corsi F, Fiandra L, de Palma C, et al. HER2 expression in breast cancer cells is downregulated upon active targeting by antibodyengineered multifunctional nanoparticles in mice. ACS Nano. 2011;5(8): 6383-6393.

85. Chen J, Wu H, Han D, Xie C. Using anti-VEGF McAb and magnetic nanoparticles as double-targeting vector for the radioimmunotherapy of liver cancer. Cancer Lett. 2006;231(2):169-175.
OncoTargets and Therapy

\section{Publish your work in this journal}

OncoTargets and Therapy is an international, peer-reviewed, open access journal focusing on the pathological basis of all cancers, potential targets for therapy and treatment protocols employed to improve the management of cancer patients. The journal also focuses on the impact of management programs and new therapeutic agents and protocols on

\section{Dovepress}

patient perspectives such as quality of life, adherence and satisfaction. The manuscript management system is completely online and includes a very quick and fair peer-review system, which is all easy to use. Visit http://www.dovepress.com/testimonials.php to read real quotes from published authors. 